\title{
WestVirginiaUniversity
}

THE RESEARCH REPOSITORY @ WVU

Graduate Theses, Dissertations, and Problem Reports

2000

\section{Pregnancy intendedness among a low income population}

Amy Nicole Thomas

West Virginia University

Follow this and additional works at: https://researchrepository.wvu.edu/etd

\section{Recommended Citation}

Thomas, Amy Nicole, "Pregnancy intendedness among a low income population" (2000). Graduate Theses, Dissertations, and Problem Reports. 1112.

https://researchrepository.wvu.edu/etd/1112

This Thesis is protected by copyright and/or related rights. It has been brought to you by the The Research Repository @ WVU with permission from the rights-holder(s). You are free to use this Thesis in any way that is permitted by the copyright and related rights legislation that applies to your use. For other uses you must obtain permission from the rights-holder(s) directly, unless additional rights are indicated by a Creative Commons license in the record and/ or on the work itself. This Thesis has been accepted for inclusion in WVU Graduate Theses, Dissertations, and Problem Reports collection by an authorized administrator of The Research Repository @ WVU. For more information, please contact researchrepository@mail.wvu.edu. 
PREGNANCY INTENDEDNESS

AMONG A LOW INCOME POPULATION

Amy N. Thomas

Thesis submitted to the School of Medicine

at West Virginia University

in partial fulfillment of the requirements for the degree of

\author{
Master of Science \\ In \\ Community Health Promotion
}

Irene Tessaro, DrPH, Chair

Ken McPherson, EdD

Debbie Coen, MS

Department of Community Medicine

Morgantown, West Virginia

2000

Keywords: Pregnancy, Intendedness, Social Support, Low Income, Psychosocial Factors

Copyright 2000 Amy N. Thomas 


\begin{abstract}
Pregnancy Intendedness Among a Low Income Population
\end{abstract}

Amy N. Thomas

Introduction: In the United States, approximately 3.1 million births per year are classified as unintended. Specific Aims: This study will examine the association between pregnancy intendedness and support characteristics, key demographic factors and psychological factors in a low income population. Methods: Three interviews were conducted as part of the intensive evaluation. Questions focused on demographics, prenatal health behaviors and psychosocial factors. Results: Unintended pregnancy resulting in birth was most commonly found among non-White, poorly educated and those living in poverty. The support of the family or friends was not found to be significant when comparing it to the intendedness of the pregnancy - but the support received from the partner was found to be significant. The only psychosocial factor found significantly related to pregnancy intendedness was the mother's feelings about this pregnancy. 


\section{TABLE OF CONTENTS}

List of Tables V

\section{Chapter Title}

1. Introduction 1

A. Statement of Research Problem 1

B. Significance 2

C. Study Objectives 2

D. Research Questions \& Hypotheses 3

2. Background 5

A. Theoretical Framework 13

3. Methods 15

A. Study Population \& Program 15

B. Program Evaluation 16

C. Data Collection 16

D. Study Variables 18

1. Demographic Characteristics 18

2. Social Support 19

3. Psychological Measures 19

4. Data Analysis 20

4. Results 21

A. Main Findings 23

B. Discussion 32 
1. Sample 32

C. Limitations 36

D. Implications for Community Health 36

\section{REFERENCES} 38 APPENDICES 41
A. Epidemiologic Studies Depression Scale: CES-D 41
B. Cohen's Perceived Stress Scale 42
C. Rosenberg Self-Esteem Scale 43 


\section{LIST OF TABLES}

Table $1 \quad$ Characteristics of the Sample 22

Table 2 Associations between and demographic variables and pregnancy intendedness 25

Table 3 Association of social support and pregnancy intendedness 27

Table 4 Association of types of social support and pregnancy intendedness 29

Table 5 Relationship between pregnancy intendedness and psychosocial factors 31 


\title{
CHAPTER 1: INTRODUCTION
}

\author{
$\underline{\text { Statement of Research Problem }}$
}

In the United States, approximately 3.1 million births per year are classified as unintended, and 1.6 million of these result in abortion (Fischer et al, 1988). Many of the unintended pregnancies that result in live births have been associated with poor pregnancy outcomes. Data from the National Survey of Family Growth showed a significant association between unintended pregnancies and low birthweight (Bitto, 1997). In the past decade, studies have examined women's behaviors during pregnancy and the results on the health of the baby (Kost, 1998).

A pregnancy, intended or unintended, can cause changes in a woman's life. Her work, family and social relationships, education, and finances are among areas in the woman's life that can be adversely affected (Orr, 1997). Psychosocial well-being can also be affected (Zachariah, 1996). The burdens of an unintended pregnancy are common and inevitable. The attitude in cultures that have a much lower rate of unintended pregnancies is that these are unfortunate and rare events that occur despite our best intentions (Hogue, 1997). Women and her partner or family can be subjected to increased stress and an increase in depression, which in turn can lead to adverse health outcomes. 


\section{$\underline{\text { Significance }}$}

In the past, several studies have focused on past reports or hypothetical (Connelly, 1998) pregnancies when looking at the concept of pregnancy intendedness. This research study concentrates on the intendedness during the present pregnancy. This study will also combine factors - psychosocial, support, and demographics - which has not been investigated, to relate these to pregnancy intendedness.

Because many births in the United States are unintended, and because it is the goal of clinicians and health educators to optimize fetal growth and reduce pregnancy complications, it is important to understand whether pregnancy intendedness is associated with health outcomes of the mother and child.

The epidemic of unintended pregnancies has not gone unnoticed by researchers. Studies have shown that pregnancy intendedness is related to psychosocial factors (Orr, 1997) and (Barnet, 1996); healthy outcomes of the baby (Kost, 1995 and 1998) and (Hollander, 1995); and social support (Aaronson, 1989) and (Fischer, 1999). The extent to which these factors are influenced due to pregnancy intendedness is extremely important when related to the health of the baby and the mother.

For those women who have an unintended pregnancy, the influence of social networks is a concern. It has been suggested that greater connection to a social support system leads to positive health outcomes for mother and baby (Aaronson, 1989).

\section{Study Objectives}

This study will examine the association between pregnancy intendedness and support 
characteristics, key demographic factors and psychosocial factors in a low-income population. Several studies have been conducted comparing pregnancy intention relating to support or demographics or psychological indicators, but none have combined these issues in a research study. Looking at these issues will influence the composition of prenatal care programs.

\section{Research Questions \& Hypotheses}

This study will focus on the following research questions and hypotheses: Research Question I: What demographic factors are related to pregnancy intendedness? Research Question II: What is the relationship between pregnancy intendedness and social support?

Hypothesis I: Compared to those pregnant women who do not want a pregnancy at the present time or in the future (unintended), pregnant women who wanted this pregnancy perceive more support for the pregnancy from significant others (baby's father, family, friends).

Hypothesis II: Compared to those pregnant women who do not want a pregnancy at the present time or in the future (unintended), pregnant women who wanted this pregnancy are more likely to have supportive relationships

Research Question III: What is the relationship between psychological indicators and pregnancy intendedness?

Hypothesis III: Compared to those pregnant women who do not want a pregnancy 
at the present time or in the future (unintended), pregnant women who wanted this pregnancy are more positive about the pregnancy.

Hypothesis IV: Compared to those pregnant women who do not want a pregnancy at the present time or in the future (unintended), pregnant women who wanted this pregnancy have more favorable psychological indicators (less depression, less stress, better selfesteem). 


\section{CHAPTER 2: BACKGROUND}

Several studies have been conducted on the issue of pregnancy intendedness. The following studies point to several factors important to consider in looking at the issue of pregnancy intendedness.

A qualitative study using in-depth semi-structured interviews with 18 women explored how women define the intention status of current, past, and hypothetical pregnancies (Fischer et al, 1999). Findings showed that most women clearly defined a difference in the terms planned and wanted, but not planned and intended. A planned and intended pregnancy carried action-oriented distinction whereas wanting was emotional. Support from family and friends toward a pregnancy may be more associated with wantedness than to intending or planning to become pregnant. Women who defined their pregnancy as wanted, even if unplanned, indicated they had support from their partners or family and security in their life circumstances such that they were pleased with this pregnancy even though it was not planned. Poor timing was not so much a factor in determining the woman's definition of unwantedness as was the adversity of her situation, which included an ambivalent partner, an unsupportive family, and inadequate financial resources. Two women had family support that they felt they could draw on in their decision to continue their pregnancy and felt that although the pregnancy was unwanted initially, it had become wanted over time. The partner's attitude toward the pregnancy was prominent in all but one case, including instances where the study participants had other means of support, such as adequate financial resources, family 
members who approved of the pregnancy, or government assistance. Classifying pregnancies as intended, or mistimed, or unwanted may be a problem for women who have not decided on a lifetime reproductive choices (Kaufmann et al, 1997).

A relationship between intendedness and wantedness was found among a sample of predominantly white, middle-class residents of the San Francisco area (Miller, 1974). The data from this study suggested that a relationship was found between the concepts of wantedness and intendedness. High intendedness was found associated with high wantedness; but medium and low intendedness are associated with a wide range of wantedness.

Some studies, such as Sable (1999), suggest that pregnancy intentions may not be a useful variable to examine for research on maternal and child health outcomes. Sable, who served as a counselor at an abortion clinic in the 1970's, states that a "woman's ambivalence about pregnancy and the unconscious wish to become pregnant even if one doesn't really want a baby - are powerful forces that complicate the whole issue of intendedness".

Unfortunately, there is not a uniform questionnaire used to survey pregnant women regarding the intendedness of their pregnancy. The PRAMS (Pregnancy Risk Assessment Survey), NMHIS (National Maternal and Infant Health Survey), and the NNS (National Natality Survey) were among those surveys examined. All of the surveys classify pregnancies into categories of intendedness after only a few questions are asked (Peterson, 1997). The issue of intendedness is a very complex one. Such limited information can not clearly classify a pregnancy as wanted, unwanted, intended or 
unintended. The researchers concluded that current information available from national surveys is not comparable due to different survey questions, inclusion criteria, and timing of interviews. What are often categorized as unintended, may actually be unwanted two different concepts.

Depressive symptoms were found to be substantially higher for women with unintended pregnancies. Women in this study with an unintended pregnancy were found to demonstrate decreased overall satisfaction of life, elevated depressive symptoms and diminished support from the father (Orr, 1997). Along with depressive symptoms, this study examined social support from the baby's father and exposure to stressors. A large percentage of women who reported their pregnancy as unintended also reported receiving low support from the father of the baby and decreased overall life satisfaction. The sample in this study consisted of socioeconomically disadvantaged, African-American women, a majority had a high-school education, one-third were employed and approximately $73 \%$ were single. Those women with unwanted pregnancies were more likely than those with intended pregnancies to report higher levels of exposure to stressors $(\mathrm{p}=.01)$. Higher levels of depressive symptoms were also reported by $10.2 \%$ of those with mistimed pregnancies and by $14.7 \%$ of those who were unsure of the intendedness of the pregnancy.

Depressive factors were found common among teenage girls who are pregnant or have recently given birth (Barnet, 1996). A group of teens attending an adolescent pregnancy and parenting program reported their depressive symptoms and social support during the third trimester of pregnancy and at four-months postpartum. Forty-two 
percent had significant depressive symptoms during the third trimester. Stress levels increased significantly from the third trimester to the postpartum period and were positively associated with depressive symptoms. Increased rates of depressive symptoms were found when conflict with the baby's father had occurred. Receiving social support from the adolescent's mother or the baby's father was associated with lower rates of depression.

The relationship with partner was found to be significant predictors of psychological well-being during pregnancy (Zachariah, 1996). For the women in the study, social support demonstrated direct positive effects on psychological well-being. Women taking part in this study were 18 or older, married, medically healthy and experiencing the first live-born infant.

Adolescent girls who reported they "wanted a baby" as a reason for pregnancy were compared to those who reported that the pregnancy "just happened" (Rubin, 1999). When examined at 24 months postpartum, those who wanted a baby were more likely to be married to the father of the baby, be financially supported by him, and received child care assistance from him. It was concluded that intentional pregnancy teens had better financial status and their relationship with the father of the baby was better than those with an unintended pregnancy.

Among women who have ever been married, the prevalence of wanted births typically increases with age (Kaufmann et al, 1997). A previous study (Kost, 1995) compared pregnancy intendedness and differences by mothers' sociodemographic factors. In this study, $57 \%$ of the births were categorized as intended. The level of 
unintended pregnancies was high among the following sociodemographic categories age 15-17, women living below the poverty level, single, Black and less than 12 years of education. Black women, in this study, were more likely to categorize their pregnancy as unwanted or mistimed. Black women were also more likely to mistime a wanted birth. Analysis indicated that births to unmarried women - whether formerly married or never married - are less likely than those pregnancies to married women to be wanted and more likely to be unintended.

Five socioeconomic measures were evaluated from data collected from PRAMS. Education and poverty status are common socioeconomic indicators, but also included in the study was participation in a special supplemental food program, such as WIC, residential crowding and Medicaid payment for delivery (Gazmararian, 1996). Findings suggested that the likelihood that the pregnancy was unintended was significantly related to each socioeconomic measure. Among women younger that were 20 and unmarried, the association strength was greatly reduced and not significant. It was found that among women younger than 20 , the likelihood that the pregnancy was unintended was significantly less for those with less than 12 years of education than for those with more than 12 years of education. The strongest association between socioeconomic factors examined showed that poor/non-poor status had the strongest relationship with unintended pregnancy. The distribution of maternal behaviors indicated that $34.9 \%$ of respondents smoked during the three months prior to pregnancy, $31.7 \%$ had delayed or no prenatal care and 40.2\% had an unintended pregnancy (Gazmararian 1996).

Women who have planned or intended pregnancies were found to have better 
health outcomes of their infant (Kost, 1998). Women with intended pregnancies were found to recognize the early signs of pregnancy (within the first six weeks), thus receiving prenatal care earlier and presenting to at least $90 \%$ of the recommended visits. These women were also more likely than women with unintended pregnancies to quit smoking, gain the recommended amount of weight, take vitamins, and quit or reduce alcohol consumption. Another study found a decrease of caffeinated beverage consumption was seen in women with an intended pregnancy (Hellerstedt, 1998). Social and demographic characteristics, Kost concluded, are important predictors of pregnancyrelated behavior. In this study, demographics were very different than the studies discussed previously. The majority of women were 29 or older, $37 \%$ had a college education, and $56 \%$ reported annual income above $\$ 45,000$. Both the intendedness of a pregnancy and the mother's social and demographic characteristics are important indicators of pregnancy-related behavior (Kost, 1998). Most of all women who had a live birth received prenatal care, but only about two-thirds began prenatal care during the first trimester. Hollander (1995) concluded that teens were far less likely to receive early prenatal care, have a mistimed pregnancy and to see a private physician for prenatal care.

The influence of social support on receiving prenatal care, positive health behaviors and attitudes was examined among a sample of 300 women who were primarily poor and Black (Giblin et al, 1990). The presence of social support was correlated with positive health behaviors, not using drugs and adequate health resources. Norbeck and Anderson examined the stability and effects of life stress, social support, and anxiety among low-income women. The researchers hypothesized that social support 
will buffer effects of life stress on anxiety at Time 1 (mid-pregnancy), Time 2 (latepregnancy), and in the prospective test of these relationships. Significant social support from the pregnant woman's partner was found significant - accounting for 3\% of the variance in anxiety. As predicted by the hypothesis, the group with the lowest anxiety level was the high-support/low-stress group. The advocacy role for nurses on behalf of low-income women was a suggested priority for medical providers working with this population (Norbeck, 1989). In the United States, unintended pregnancy resulting in birth is most common among non-white, poorly educated, adolescent and those living in poverty (Hellerdest, 1998).

The partner's attitude toward the pregnancy was prominent when the woman was defining the status of her pregnancy in a 1999 study. This support was a factor even if the woman had other means of support, such as adequate financial resources, family members' support of the pregnancy, family members who could provide support after the birth of the child or government assistance (Fischer et al, 1999). Married women in this study were more likely to have a planned and wanted pregnancy. However, women who became pregnant without making the decision to do so with their spouse reported that their husband's support influenced the pregnancy becoming wanted.

A unique study examined the father's needs during the pregnancy (Kleiner, 1992). The male experience during the pregnancy depends on two primary issues: the way the expectant father deals with emotions, and the quality of communication between the couple. The father-to-be needs just as much support as the mother-to-be and he rarely asks for or receives it. 
Connelly (1998) found in a study that included pregnant and non-pregnant adolescents that the common view that adolescent pregnancy is related to a lack of hopefulness was not supported. Adolescents in this study were affiliated with support strong networks. The support perceived may have resulted from attention to ensure adequate prenatal care, the need to complete education and the symbolic significance of motherhood.

In summary, studies point to several factors with pregnancy intendedness: support from partners and family; sociodemographic characteristics, such as age, race, education, and marital status; and psychological measure, especially depression. Few of these studies have looked at support from significant others or characteristics of women's social networks, including support available from these networks. 


\section{Theoretical framework}

Individuals learn behaviors mainly through primary group associations within their own social networks (friends, family, etc.). The term social network refers to a person-centered web of social relationships (Glanz et al, 1997). Informal social networks (friends and family) have been shown to be important in influencing positive health behaviors among women and minorities.

The provision of social support is one of the important functions of social relationships. Thus, social networks are linkages between people that may or may not provide social support and that may serve other functions in addition to that support. Social support is the functional content of relationships, which can be categorized along four broad types of supportive behavior. The first is emotional support. This type involves the components of empathy, love, trust and caring. Another category is instrumental support, which involves tangible aid and services that directly assist a person in need. Informational support is the provision of advice, suggestions, and information that a person can use in addressing problems. The fourth type is appraisal support, which includes giving information and advice which is useful in self-evaluation, or it can be termed "constructive criticism".

The study of social support was a major concept in the research of John Cassel (1976). Cassel suggested that social support serves as a key psychosocial protective factor that reduces individuals' vulnerability to the negative effects of stress on life. He concluded that social support might influence the incidence and prevalence of a wide 
array of health outcomes.

Social networks and social support can enhance an individual's ability to access new contacts and information and to identify and solve problems. If the support provided helps to reduce uncertainty and unpredictability or helps to produce desired outcomes, then a sense of personal control over specific situations and life domains will be enhanced (Glanz et al, 1997).

Social support has been shown to have a significant affect as a "stress-buffer". A variety of techniques to manage stress and to reduce the ill effects of the stressors have been developed and tested in recent years. Social support can influence how a person adapts psychologically to a stressful event - such as an unintended pregnancy. A supportive environment can also protect against stress by providing opportunities for individuals to explore different coping options. 


\section{CHAPTER 3: METHODS}

\section{$\underline{\text { Study Population \& Program }}$}

The Maternal Outreach Worker (MOW) Baby Love program was funded in 1992, by the Kate B. Reynolds Health Care Trust Fund to decrease poor pregnancy outcomes among at-risk women in North Carolina. This social support program was designed to take place in 24 counties in North Carolina. The program was designed to combat North Carolina's high infant mortality rate - one of the highest in the country. One of the main objectives of the MOW program was to enhance Medicaid's Maternity Care Coordination Program through home visits and other outreach services. Nonprofessional, paid health-care workers from the respective program communities provided the outreach services. The MOW Program had five strategies to meet the goal of reducing infant mortality in the state. These five strategies are: (1) encourage women to enter earlier into prenatal programs such as the WIC nutrition program; (2) encourage the regularity of prenatal visits and consistency of prenatal care; (3) educate new mothers on healthful behaviors and effective parenting skills; (4) increasing the time between pregnancies; and finally, (5) to reduce the incidence rate of unplanned pregnancies.

The MOW program provided services to eligible infants up to one year of age. The program objectives for these infants are: (1) to encourage earlier and continuous participation in well-baby programs; (2) improved birthweight; and (3) increased utilization of support services such as WIC and other Medicaid services.

To meet program objectives, Maternal Outreach Workers (MOW) were hired and trained. This three-month training included 60 hours of basic training for assessing client 
living situations and access to appropriate resources. The MOW practitioner training also involved skill development in the areas of problem solving, effective communication, emotional support and client advocacy.

Each MOW had 25-30 clients in need of intensive one-on-one support services. These were Medicaid eligible women, who were 28 or fewer weeks pregnant. MOW's were to follow these women until their baby was one year old. The clients were identified by a Maternity Care Coordinator and then referred to an MOW case worker. Some criteria used in the client referral included substance use, young age, history of family violence, social or geographic isolation and a history of noncompliance to health care or social services.

\section{$\underline{\text { Program Evaluation }}$}

A two-pronged evaluation was designed to determine the effectiveness of the North Carolina Baby Love Maternal Outreach Worker (Tessaro et al, 1997) Program. An intensive interview was conducted with participants and non-participants to determine impact of the program and a program-wide evaluation was conducted to determine birth outcomes among those who did not participate in the program. Major components of the program's effectiveness were based on pregnancy outcomes, health behaviors of the participants, and the health status of their infants.

\section{$\underline{\text { Data Collection }}$}

Three interviews (during pregnancy, one month postpartum and one year after the 
birth of the baby) were conducted as part of the intensive evaluation. The present study uses interview data with those women who completed the first interview during pregnancy.

Interview subjects were selected from counties participating and those not participating in the MOW program. The interview participants were selected and recruited by a Maternal Care Coordinator according to pre-existing criteria. Participants for the intensive interview evaluation were recruited based on whether they were at less than 28 weeks gestation, were receiving Maternal Coordination Care from a County Health Department and they met the qualifications for the MOW Baby Love Program. The women also possessed one or more of the following high-risk characteristics: young teen, sub7stance abuse, lacking social support, non-compliance of care or mental illness and depression. Referrals to the program were most often based on a lack of social support. Through this selection process, 705 women agreed to participate in this component of the evaluation: 332 were from comparison counties and 373 were from MOW program counties.

Data were collected in this study using structured, face-to-face interviews. Each interviewer was trained and each interview took between 45 and 90 minutes. A day-long training session on interviewing techniques and the use of the questionnaires. Over the three years of data collection, 28 interviewers were used in the study. The interview questions focused on demographics (income, race, amount of schooling completed, etc.), perceived needs, psychological function, informal social support networks such as support from friends and family, and substance abuse during pregnancy. 


\section{$\underline{\text { Study Variables }}$}

Pregnancy intendedness was assessed by the following question:

Thinking back, just before you got pregnant, would you say you:

a) wanted to become pregnant at this time,

b) did not want to become pregnant at that time, but wanted a child sometime in the future, or

c) did not want to become pregnant at that time or any time in the future.

The pregnancy was categorized as "wanted" if the respondent stated that the pregnancy was wanted at this time. Likewise, a pregnancy was unwanted if the responded stated either choice $\mathrm{b}$ or $\mathrm{c}$.

\section{$\underline{\text { Demographic Characteristics }}$}

Demographic factors were divided into several categories. For purposes of this study, race was classified as "white" or "non-white". The age of mothers participating in the study was classified as less than 17, 18-19, or over 20. Education level was determined by either did or did not graduate from high school. Marital status was divided into the categories: single, married, separated, widowed, divorced, or never married. Weeks gestation when first presented to prenatal care was categorized as first trimester, within the first 13 weeks; second trimester, 14-26 weeks; and the third trimester, 26 weeks or more determined this classification. Number of pregnancies were classified as (1) first or (2) second or more pregnancies. Whether the women had used birth control in the year before pregnancy was classified as yes or no. 


\section{$\underline{\text { Social Support }}$}

Informal social networks were subdivided into structural and functional components. Structural support was further divided into sources of and frequency of support. The source of the support was further subdivided into two categories - support from a male or female. The frequency of support was measured on a scale ranging from "never received" to "often received". Social support variables included support from the father of the baby, interaction with friends and relatives, people they feel "close to", among others.

\section{$\underline{\text { Psychological Measures }}$}

Depressive symptoms were assessed with the 20-item self-report Centers for Epidemiologic Studies Depression Scale (CES-D), see Appendix A for a complete list (Radloff, 1997). Respondents were asked to say how many days in the last week they experienced a range of behaviors (loss of appetite, sleep disturbance, emotional and social patterns) or feelings (elated, hopeful, sad, fearful). High internal consistency reliability levels have been reported for the scale (coefficient alpha .90 or above). The total score of 60 or more defined the category of "high depression".

Perceived stress was assessed using the Perceived Stress Scale (PSS) (Cohen, 1983), a 14-item self-report measure (Appendix B) which assesses the degree to which situations during the last month are appraised as stressful. Items were rated on a five point Likert scale from never to very often. High internal consistency has been reported for this scale (coefficient alpha .85 and test-retest reliability .85 ). A total score of 36 or more was defined as "high stress". 
Self-esteem was assessed using Rosenberg's Self-Esteem scale (Rosenberg), a 10item self-report measure dealing with issues of self-worth and respect (Appendix C). Items were measured on a four point Likert scale from strongly agrees to strongly disagree. Test-retest reliability for this scale ranges from .85 to .88 . The total score of 25 or less was defined as "low self-esteem".

Feelings about pregnancy were assessed with an open-ended question and were content coded as positive, negative at first then positive, ambivalent and negative about pregnancy.

\section{$\underline{\text { Data Analysis }}$}

Frequency distributions were calculated for all study variables. Hypotheses were tested using chi square analysis since all variables were measured at nominal and ordinal levels. Associations between pregnancy intendedness and sociodemographic, social support, and psychological variables were considered significant at the .05 level. 


\section{CHAPTER 4: RESULTS}

Table 1 shows the characteristics of the sample. Program participants who were 20 or older, made up the largest portion $(45.8 \%)$ of the study population followed by those 17 or younger $(34.6 \%)$, and ages $18-19(19.6 \%)$. White participants made up $36.5 \%$ of the sample and non-Whites, $63.6 \%$. The "non-White" category was made up of those who were Black, Native American, Hispanic, Asian or "other". Race was recorded by observation. Of all participants, $13.9 \%$ were married, $4.3 \%$ were divorced, $7.7 \%$ were separated, $0.4 \%$ were widowed, and $73.8 \%$ were never married. Those who graduated high school made up $37.3 \%$ of the study group $-62.7 \%$ did not complete high school. The trimester in which the study participant entered the study was: $17.6 \%$ in the first trimester (<13 weeks gestation), 55.8\% in the second trimester (14-26 weeks gestation), $25.9 \%$ in the third trimester ( $>26$ weeks). Those women that were uncertain of the gestation period made up $0.7 \%$ of the study group. The women who used birth control in the year preceding their pregnancy made up $70.9 \%$ of the study population $-29.1 \%$ did not use birth control. Study participants who were pregnant for the first time made up $47.1 \%$ of the study population. Those having their second or other baby made up $52.9 \%$ of the group. Of the 705 women, 19.4\% (N=137) intended to become pregnant, while $80.6 \%$ did not want to become pregnant at this time. 
Table 1: Characteristics of the sample.

\begin{tabular}{|c|c|c|}
\hline & $\mathrm{N}$ & $\%$ \\
\hline \multicolumn{3}{|l|}{ Age } \\
\hline \multirow{3}{*}{$\begin{array}{l}<17 \\
18-19 \\
20+\end{array}$} & 244 & 34.6 \\
\hline & 138 & 19.6 \\
\hline & 323 & 45.8 \\
\hline \multicolumn{3}{|l|}{ Race } \\
\hline \multirow{2}{*}{$\begin{array}{l}\text { White } \\
\text { Non-White }\end{array}$} & 257 & 36.5 \\
\hline & 448 & 63.5 \\
\hline \multicolumn{3}{|l|}{ Marital Status } \\
\hline \multirow{5}{*}{$\begin{array}{l}\text { Married } \\
\text { Divorced } \\
\text { Separated } \\
\text { Widowed } \\
\text { Never Married }\end{array}$} & 98 & 13.9 \\
\hline & 30 & 4.3 \\
\hline & 54 & 7.7 \\
\hline & 3 & 0.4 \\
\hline & 520 & 73.8 \\
\hline \multicolumn{3}{|l|}{ Intendedness } \\
\hline \multirow{2}{*}{$\begin{array}{l}\text { Want Now } \\
\text { Did Not Want Now }\end{array}$} & 137 & 19.4 \\
\hline & 568 & 80.6 \\
\hline \multicolumn{3}{|l|}{ Education } \\
\hline \multirow{2}{*}{$\begin{array}{l}<\text { High School } \\
\text { HS Graduate }\end{array}$} & 441 & 62.7 \\
\hline & 262 & 37.3 \\
\hline
\end{tabular}




\section{$\underline{\text { Main Findings }}$}

Research question 1: What demographic factors are related to pregnancy intendedness?

Table 2 compares selected demographic factors and the relationship to pregnancy intendedness. Women who reported they wanted this pregnancy at this time were older than those who reported they did not want to become pregnant either at this time or in the future $(\mathrm{p}=.001)$. For those women under age 17, 20.4\% wanted the pregnancy compared to $38.0 \%$ who did not.

This table also shows the relationship of ethnicity to pregnancy intendedness. Compared to non-Whites, Whites were more likely to have a wanted pregnancy, $\mathrm{p}=.001$. A higher percentage, $68.1 \%$, of non-White women reported they did not want this pregnancy at this time.

Those who were never married were more likely (79.4\%) to have an unwanted pregnancy than those who were married $(\mathrm{p}=.001)$. Only $9.7 \%$, who were married had an unwanted pregnancy.

Also found significant, $\mathrm{p}=.005$, was the relationship between currently having a boyfriend and having a wanted or unwanted pregnancy. Those women who did not have a boyfriend were more likely to have an unwanted pregnancy. Those women who wanted the pregnancy at this time were significantly more likely to be a high school graduate compared to those who did not complete high school $(\mathrm{p}=.009)$.

Women who presented for prenatal care in their first trimester of pregnancy were more likely to report they wanted this pregnancy at this time $(\mathrm{p}=.011)$. Those women 
who reported they were not using birth control were more likely to have an unwanted pregnancy at this time. Those women who reported they did use birth control in the year before pregnancy were more likely to say this pregnancy was unintended ( $\mathrm{p}=.007)$. 
Table 2: Associations between sociodemographic variables and pregnancy intendedness

\begin{tabular}{|c|c|c|c|c|}
\hline & Wanted & Unwanted & & \\
\hline & $\mathrm{N}(\%)$ & $\mathrm{N}(\%)$ & Chi-square & p-value \\
\hline \multicolumn{3}{|l|}{ Age } & \multirow{4}{*}{15.55} & \multirow{4}{*}{.001} \\
\hline \multirow{3}{*}{$\begin{array}{l}<17 \\
18-19 \\
20+\end{array}$} & $28(20.4)$ & $216(38.0)$ & & \\
\hline & $30(21.9)$ & $108(19.0)$ & & \\
\hline & $79(57.7)$ & $244(43.0)$ & & \\
\hline \multicolumn{3}{|l|}{ Ethnicity } & \multirow{3}{*}{26.56} & \multirow{3}{*}{.001} \\
\hline White & $76(55.5)$ & $181(31.9)$ & & \\
\hline Non-White & $61(44.5)$ & $387(68.1)$ & & \\
\hline \multirow{6}{*}{$\begin{array}{l}\text { Marital Status } \\
\text { Married } \\
\text { Divorced } \\
\text { Separated } \\
\text { Widowed } \\
\text { Never Married }\end{array}$} & \multicolumn{2}{|l|}{ 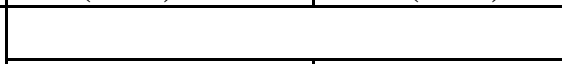 } & \multirow{6}{*}{59.59} & \multirow{6}{*}{.001} \\
\hline & $43(31.4)$ & $55(9.7)$ & & \\
\hline & $12(8.7)$ & $18(3.2)$ & & \\
\hline & $13(9.5)$ & $41(7.2)$ & & \\
\hline & $0(0)$ & $3(0.1)$ & & \\
\hline & $69(50.4)$ & $451(79.4)$ & & \\
\hline \multirow{3}{*}{$\begin{array}{l}\text { Currently have } \\
\text { boyfriend? } \\
\text { Yes } \\
\text { No } \\
\end{array}$} & & & \multirow{3}{*}{7.26} & \multirow{3}{*}{.005} \\
\hline & $64(80)$ & $300(64.6)$ & & \\
\hline & $16(20)$ & $164(35.3)$ & & \\
\hline \multicolumn{3}{|l|}{$\begin{array}{l}\text { High School } \\
\text { Graduate }\end{array}$} & \multirow{3}{*}{6.91} & \multirow{3}{*}{.009} \\
\hline Yes & $64(47.1)$ & $198(34.9)$ & & \\
\hline No & \multicolumn{2}{|r|}{$369(65.1)$} & & \\
\hline \multirow{4}{*}{$\begin{array}{l}\text { Trimester of } \\
\text { pregnancy } \\
<13 \text { weeks } \\
14-26 \text { weeks } \\
>26 \text { weeks }\end{array}$} & & & \multirow{4}{*}{10.48} & \multirow{4}{*}{.011} \\
\hline & $35(25.7)$ & 89 (15.7) & & \\
\hline & $75(55.1)$ & $318(56)$ & & \\
\hline & $26(19.1)$ & $156(27.5)$ & & \\
\hline \multicolumn{3}{|l|}{$\begin{array}{l}\text { Birth control } \\
\text { used? }\end{array}$} & \multirow{3}{*}{7.54} & \multirow{3}{*}{.007} \\
\hline Yes & $84(61.3)$ & $415(73.2)$ & & \\
\hline No & $53(38.7)$ & $152(26.8)$ & & \\
\hline \multicolumn{3}{|l|}{ First pregnancy } & \multirow{3}{*}{3.29} & \multirow{3}{*}{.070} \\
\hline Yes & $55(40.2)$ & $277(48.8)$ & & \\
\hline No & $82(59.9)$ & $291(51.2)$ & & \\
\hline
\end{tabular}


Research question II: What is the relationship between pregnancy intendedness and social support?

Table 3 shows the relationship between pregnancy social support, living with a significant other, and pregnancy intendedness. Women who received strong support from the father of the baby $(\mathrm{p}=.001)$, family $(\mathrm{p}=.013)$, and friends $(\mathrm{p}=.008)$ were more likely to report they wanted their pregnancy at this time.

If the woman lived with the father of the baby she was significantly more likely to want this pregnancy $(\mathrm{p}=.001)$. This was the opposite if the woman lived with her mother. If the mother of the study participant lived with her pregnant daughter, the pregnancy was more likely to be unwanted $(\mathrm{p}=.001)$. 
Table 3: Association of social support and pregnancy intendedness

\begin{tabular}{|c|c|c|c|c|}
\hline & Wanted & Unwanted & & \\
\hline & $\mathrm{N}(\%)$ & $\mathrm{N}(\%)$ & Chi-square & p-value \\
\hline \multicolumn{5}{|c|}{ Father of Baby } \\
\hline \multirow{5}{*}{$\begin{array}{l}\text { How the father } \\
\text { of baby feels } \\
\text { Very supp. } \\
\text { Supportive } \\
\text { Unsupportive } \\
\text { Very unsupp. }\end{array}$} & & & \multirow{5}{*}{38.8} & \multirow{5}{*}{.001} \\
\hline & $95(69.3)$ & $225(40.3)$ & & \\
\hline & $30(21.9)$ & $198(35.5)$ & & \\
\hline & $4(2.9)$ & $56(10.0)$ & & \\
\hline & $8(5.8)$ & $79(14.2)$ & & \\
\hline \multicolumn{3}{|l|}{ Lives with } & \multirow{3}{*}{63.82} & \multirow{3}{*}{.001} \\
\hline \multirow{2}{*}{$\begin{array}{l}\text { Yes } \\
\text { No }\end{array}$} & $73(53.3)$ & $112(19.8)$ & & \\
\hline & $64(46.7)$ & $454(80.2)$ & & \\
\hline \multicolumn{5}{|c|}{ Family } \\
\hline \multirow{5}{*}{$\begin{array}{l}\text { How family } \\
\text { feels } \\
\text { Very supp. } \\
\text { Supportive } \\
\text { Unsupportive } \\
\text { Very unsupp. }\end{array}$} & & & \multirow{5}{*}{10.34} & \multirow{5}{*}{.013} \\
\hline & $80(59.7)$ & $266(47.4)$ & & \\
\hline & $37(27.6)$ & $239(42.6)$ & & \\
\hline & $10(7.5)$ & $36(5.1)$ & & \\
\hline & $7(5.2)$ & $20(3.6)$ & & \\
\hline \multicolumn{3}{|l|}{$\begin{array}{l}\text { Lives with } \\
\text { mom }\end{array}$} & \multirow{3}{*}{15.57} & \multirow{3}{*}{.001} \\
\hline \multirow{2}{*}{$\begin{array}{l}\text { Yes } \\
\text { No }\end{array}$} & $39(28.5)$ & $267(49.1)$ & & \\
\hline & $98(71.5)$ & $300(52.9)$ & & \\
\hline \multicolumn{5}{|c|}{ Friends } \\
\hline \multirow{5}{*}{$\begin{array}{l}\text { How friends } \\
\text { feel } \\
\text { Supportive } \\
\text { Very supp. } \\
\text { Unsupportive } \\
\text { Very unsupp }\end{array}$} & & & \multirow{5}{*}{11.78} & \multirow{5}{*}{.008} \\
\hline & $69(52.3)$ & $206(37.2)$ & & \\
\hline & $50(37.9)$ & $296(53.4)$ & & \\
\hline & $4(3.0)$ & $22(4.0)$ & & \\
\hline & $9(6.8)$ & $30(5.4)$ & & \\
\hline \multirow{3}{*}{$\begin{array}{l}\text { Lives } \\
\text { Alone } \\
\text { Not alone }\end{array}$} & & & \multirow{3}{*}{0.031} & \multirow{3}{*}{0.862} \\
\hline & $6(4.4)$ & $23(4.1)$ & & \\
\hline & $131(95.6)$ & $545(96.0)$ & & \\
\hline
\end{tabular}


Table 4 shows the relationship between types of general social support and pregnancy intendedness. In terms of instrumental support, if a woman reports that the father of the baby can help with the pregnancy, she is more likely to also report the pregnancy was wanted $(\mathrm{p}=.001)$. No association was found for help from family or friends.

There was no significant association found between pregnancy intendedness and emotional support, in the sense of "feeling close" with a friend ( $\mathrm{p}=.077)$ or the family $(p=.204)$. Frequency of correspondence between the woman and her friends showed a significant $(\mathrm{p}=.015)$ relationship. Those women who interacted more with friends were more likely to have an unwanted pregnancy, possibly indicating less contact with family or the father of the baby. 
Table 4: Association of types of social support and pregnancy intendedness

\begin{tabular}{|c|c|c|c|c|}
\hline & Wanted & Unwanted & & \\
\hline & $\mathrm{N}(\%)$ & $\mathrm{N}(\%)$ & Chi square & $\mathrm{p}$-value \\
\hline \multicolumn{5}{|c|}{ Instrumental Support } \\
\hline \multirow{3}{*}{$\begin{array}{l}\text { Father can help } \\
\text { Yes } \\
\text { No }\end{array}$} & & & \multirow{3}{*}{14.68} & \multirow{3}{*}{.001} \\
\hline & $59(43.1)$ & $150(26.4)$ & & \\
\hline & $78(57)$ & $418(73.6)$ & & \\
\hline \multicolumn{3}{|l|}{ Family can help } & \multirow{3}{*}{0.279} & \multirow{3}{*}{.597} \\
\hline Yes & $60(43.8)$ & $263(46.3)$ & & \\
\hline No & $77(56.2)$ & $305(53.7)$ & & \\
\hline \multicolumn{3}{|l|}{ Friend can help } & \multirow{3}{*}{0.040} & \multirow{3}{*}{.842} \\
\hline \multirow{2}{*}{$\begin{array}{l}\text { Yes } \\
\text { No }\end{array}$} & $41(30.2)$ & $166(29.3)$ & & \\
\hline & $95(69.9)$ & $401(70.7)$ & & \\
\hline \multicolumn{5}{|c|}{ Emotional Support } \\
\hline & \multicolumn{4}{|l|}{ Feel Close } \\
\hline \multirow{3}{*}{$\begin{array}{c}\text { Friend } \\
\text { None } \\
1+ \\
\end{array}$} & & & \multirow{3}{*}{3.29} & \multirow{3}{*}{.077} \\
\hline & $32(23.4)$ & $95(16.7)$ & & \\
\hline & $105(76.6)$ & $473(83.3)$ & & \\
\hline \multirow{4}{*}{$\begin{array}{c}\text { Family } \\
\text { None } \\
1+\end{array}$} & & & \multirow{3}{*}{1.70} & \multirow{3}{*}{.204} \\
\hline & $21(15.3)$ & $64(11.3)$ & & \\
\hline & $116(84.7)$ & $503(88.7)$ & & \\
\hline & \multicolumn{4}{|c|}{ Amount of correspondence } \\
\hline \multirow{3}{*}{$\begin{array}{l}\text { Friend } \\
\text { Rarely } \\
1+\text { per week }\end{array}$} & & & \multirow{3}{*}{6.03} & \multirow{3}{*}{.015} \\
\hline & $57(41.6)$ & $80(30.6)$ & & \\
\hline & $80(58.4)$ & $394(69.4)$ & & \\
\hline \multirow{3}{*}{$\begin{array}{l}\text { Family } \\
\text { Rarely } \\
1+\text { per week }\end{array}$} & & & \multirow{3}{*}{.067} & \multirow{3}{*}{.796} \\
\hline & $30(21.9)$ & $130(22.9)$ & & \\
\hline & $107(78.1)$ & $437(77.1)$ & & \\
\hline
\end{tabular}


Research question III: What is the relationship between psychological indicators and pregnancy intendedness?

There is a high significance $(\mathrm{p}=.001)$ associated between pregnancy intendedness and only one of the four psychosocial factors examined. Women who wanted the pregnancy at this time were more likely to feel positive about the pregnancy $(\mathrm{p}=.001)$

There was no relationship found between pregnancy intendedness and self-esteem $(\mathrm{p}=.46)$, perceived stress $(\mathrm{p}=.95)$, or depression $(\mathrm{p}=.19)$. Overall, few women in this population reported high stress $(10 \%)$ or depression $(<15 \%)$ (Table 5). 
Table 5: Relationship between pregnancy intendedness and psychosocial factors

\begin{tabular}{|c|c|c|c|c|}
\hline & Wanted & Unwanted & & \\
\hline & $\mathrm{N}(\%)$ & $\mathrm{N}(\%)$ & Chi-square & p-value \\
\hline \multirow{5}{*}{$\begin{array}{l}\text { Feelings about } \\
\text { this pregnancy } \\
\text { Positive } \\
\text { Negative then } \\
\text { positive } \\
\text { Ambivalent } \\
\text { Negative }\end{array}$} & & & \multirow{5}{*}{23.85} & \multirow{5}{*}{.001} \\
\hline & $110(80.3)$ & $345(61.0)$ & & \\
\hline & $2(1.5)$ & $80(14.1)$ & & \\
\hline & $13(9.5)$ & $81(14.3)$ & & \\
\hline & $12(8.8)$ & $60(10.6)$ & & \\
\hline \multirow{3}{*}{$\begin{array}{c}\text { Self-esteem } \\
\text { Positive } \\
\text { Negative }\end{array}$} & & & \multirow{3}{*}{0.561} & \multirow{3}{*}{.462} \\
\hline & $17(12.4)$ & $58(10.2)$ & & \\
\hline & $120(87.6)$ & $510(89.8)$ & & \\
\hline \multirow{3}{*}{$\begin{array}{l}\text { Perceived stress } \\
\text { High } \\
\text { Low }\end{array}$} & & & \multirow{3}{*}{0.003} & \multirow{3}{*}{.954} \\
\hline & $14(10.2)$ & $57(10.1)$ & & \\
\hline & $123(89.8)$ & $510(89.1)$ & & \\
\hline \multicolumn{3}{|l|}{ Depression } & \multirow{3}{*}{1.787} & \multirow{3}{*}{.194} \\
\hline High CES-D & $20(14.6)$ & $60(10.6)$ & & \\
\hline Low CES-C & $117(85.4)$ & $508(89.4)$ & & \\
\hline
\end{tabular}




\section{$\underline{\text { Discussion }}$}

$\underline{\text { Sample }}$

The distribution and similarities among various sociodemographic factors were found among the MOW program participants. Participants in the MOW program that were recruited for interviewing were selected based on whether they were at less than 28 weeks gestation, receiving Maternal Coordination Care from a County Health Department and they met the qualifications for the Baby Love Program. The women also possessed one or more of the following high-risk characteristics: young teen, substance abuse, lacking social support, non-compliance of care or mental illness and depression. Referrals to the program were most often based on a lack of social support. Through this selection process, 705 women agreed to participate in this component of the evaluation: 332 were from comparison counties and 373 were from MOW program counties.

Program participants who were 20 or older, made up the largest portion of the study population followed by those 17 or younger, and finally, 18-19. Many of the study participants did not complete high school. If a woman used birth control and became pregnant, the pregnancy was most likely an unwanted one.

*Research question I: What demographic factors are related to pregnancy intendedness?

Of the sociodemographic factors compared with intendedness, all were found significant - except for one, first pregnancy. As reported by Hellerdest (1998) unintended pregnancy resulting in birth is most commonly found among non-White, poorly educated and those living in poverty - results of this study are similar. The 
women who were older, 20 and over, were found to be more likely to want their pregnancy at this time. Findings in this study were similar to Kost's (1995). Both studies found the level of unintended pregnancies were higher among those women age 15-17, single, non-White and did not graduate high school. As suggested by Kaufman et al (1997), this study also showed that women who have ever been married, the prevalence of pregnancy intendedness increased with age.

Women in the second trimester of pregnancy made up the majority of study participants. As suggested by Kost (1998), Gazmararain (1996), Orr (1997) and Hollander (1995), this study coincides with their findings that women with an unintended pregnancy are more likely to enroll in prenatal care later than those with an intended pregnancy. This study also found that among women with less than a high school education, the likelihood was greater that the pregnancy was unwanted. High school incompletion possibly relates to the age of study participants - many were 17 or younger.

* Research question II. What is the relationship between pregnancy intendedness and social support?

Hypothesis I: Compared to those pregnant women who do not want a pregnancy at the present time or in the future (unwanted), pregnant women who wanted this pregnancy perceive more support for the pregnancy from significant others (baby's father, family, friends).

Support received from the father of the baby was highly significant. Fischer et al 
(1998) found similar results in their study - the partner's attitude toward the pregnancy was very important in categorizing the pregnancy as intended and wanted. It is interesting to note that the father of the baby, in this study, was supportive of the pregnancy regardless of its intendedness. If the woman lived with the father of the baby, it was most likely a supportive relationship with an intended pregnancy. This is possibly related to the marital status of the couple.

Hypothesis II: Compared to those pregnant women who do not want a pregnancy at the present time or in the future (unwanted), pregnant women who wanted this pregnancy are more likely to have supportive relationships.

Family and friend support was also found to be significant when related to pregnancy intendedness. It is interesting to note, however, that instrumental support from the father of the baby was significant in association with pregnancy intendedness support from friends or family was not found significant. Similarly, the amount of correspondence with the family was not significant, but the amount of correspondence with friends was found to be significant. Emotional support was also only significant when received from friends, not from family. A large number of women with unintended pregnancies also reported receiving low support from the father. This was also seen in another study (Orr, 1997). Teens with a better relationship with the father, were more likely to have an intended pregnancy (Rubin, 1999).

Hypotheses I and II were confirmed, those with more support were more likely to 
have an intended pregnancy. Those with supportive relationships and perceived support were more likely to report an intended pregnancy.

*Research Question III: What is the relationship between psychological indicators and pregnancy intendedness?

Hypothesis III: Compared to those pregnant women who do not want a pregnancy at the present time or in the future (unintended), pregnant women who wanted this pregnancy are more positive about the pregnancy.

The only psychosocial factor found significantly related to pregnancy intendedness was the mother's feelings about this pregnancy. The other psychosocial factors (depression, self-esteem, and perceived stress) examined were not found to be significant when compared to pregnancy intendedness.

Hypothesis III was confirmed, those women that felt positive about their pregnancy were significantly more likely to have a wanted pregnancy.

Hypothesis IV: Compared to those pregnant women who do not want a pregnancy at the present time or in the future (unintended), pregnant women who wanted this pregnancy have more favorable psychological indicators (less depression, less stress, better selfesteem).

These were the most surprising results found in the study. Orr (1997) found that those who reported higher levels of depressive symptoms and low self-esteem were more likely to report an unintended pregnancy, whereas in this study, there was no significance found between self-esteem, stress or depression and pregnancy intendedness.

Hypothesis IV was rejected. No significance was found when relating 
psychosocial factors and pregnancy intendedness.

\section{Limitations}

This study must be viewed in light of its limitations. All of the data were collected in personal interviews which are subject to all of the biases associated with selfreported information. A non-random sample was used in this study. Women chosen for the study were those within close proximity to the research team although similar characteristics were found in women throughout the state in the MOW program. Third, selection bias may have been present due to the somewhat different referral patterns used by the health departments and community health centers that housed the MOW program since they had considerable autonomy in the program.

\section{$\underline{\text { Implications For Community Health }}$}

Achieving the lofty goal that all pregnancies are intended will require the adoption of new behaviors. Strategies to do so should be similar to the broad-based strategies used in smoking cessation and seat belt intervention programs. But because sexual behavior is a private one and is often surrounded by controversy, efforts to promote a new childbearing norm will clearly be more difficult than changing views on seat belt use.

It is also important for a uniform questionnaire to be developed to assess the complex issue of pregnancy intendedness. Statistics on pregnancy intendedness can not be accurately reported until this reporting system is developed.

Further research is needed to examine the effectiveness of current family planning programs. Programs must be multi-faceted, providing supplies, and information on the 
importance of a planned pregnancy.

The results of this study emphasize the importance of social support in pregnancy. Medical providers and social service workers should consider this when working with women and their significant others in the prenatal period. Supportive relationships were found to have an impact on the intendedness and wantedness of the pregnancy.

It is important to consider the needs of the father of the baby when providing prenatal care. Strategies to incorporate the family, father of the baby, and friends in support tactics for the mother of the baby is needed to better her health and baby's health and her psychosocial well-being.

Public discussion of the topic of unintended pregnancy is a necessary first step in solving this problem. The solution will require an understanding of and commitment to the belief that every pregnancy should be clearly desired at the time of conception. 


\section{REFERENCES}

Aaronson L. S. (1989) Perceived and received support: effects on health behavior during pregnancy. Nursing Research 38(1), 4-9

Barnet, B. et al. (1996) Depressive symptoms, stress, and social support in pregnant and postpartum adolescents. Archives of Pediatric and Adolescent Medicine 150, 64-9

Connelly, C. D. (1998) Hopefulness, self-esteem, and perceived social support among pregnant and nonpregnant adolescents. Western Journal of Nursing Research 20(2): 195210

Fisher R.C., Stanford, J., Jameson, P., DeWitt, J. (1999). Exploring the concepts of intended, planned, and wanted pregnancy. Journal of Family Practice 48(2), 117-22

Gazmararian J. A., Adams, M. M., Pamuk, E. R. (1996) Associations between measures of socioeconomic status and maternal health behavior. American Journal of Preventive Medicine 12(2), 108-15

Giblin, P. T., Poland, M. L.,Ager, J. W. (1990) Effects of social supports on attitudes, health behaviors and obtaining prenatal care. Journal of Community Health 15(6), 357-68 
Glanz, K. et al. Health behavior and health education, second edition 1997. Jossey-Bass inc., Publishers

Hellerstedt, W. L; Pirie, P. L. (1998) Differences in preconceptional and prenatal behaviors in women with intended and unintended pregnancies. American Journal of Public Health 88(4):663-7

Hogue, C. J. (1997) Missing the boat on pregnancy prevention. Issues in Science and Technology $13,41-6$

Hollander D. (1995) Young, Minority and disadvantaged women exhibit least favorable pregnancy-related health behavior. Family Planning Perspectives 27(6): 259-61.

Kaufmann, R. B., Morris L., Spitz, A. M. (1997) Comparison of two question sequences for assessing pregnancy intentions. American Journal of Epidemiology 145(9), 810-6

Kleiner, E. (1992) To father a pregnancy. Mothering 64, 24

Kost, K., Landry, D. L, et al. (1998) Predicting maternal behaviors during pregnancy: does intention status matter? Family Planning Perspectives 30(2), 79-89

Kost, K., Forrest, J. D. (1995) Intention status of U.S. births in 1988: differences by mothers' socioeconomic and demographic characteristics. Family Planning Perspectives $\underline{27}(1), 11-18$ 
Miller, W. B. (1974) Relationships between the intendedness of conception and the wantedness of pregnancy. The Journal of Mental and Nervous Disease 159(6), 396-405

Norbeck, J., Anderson, J. (1989) Life stress, social support, and anxiety in mid- and latepregnancy among low income women. Research in Nursing and Health 12, 281-7

Orr, S. T., Miller, C. A. (1997) Unintended pregnancy and the psychosocial well-being of pregnant women. Women's Health Issues 7(1), 38-46

Peterson, R., Moos, M. (1997) Defining and measuring unintended pregnancy: issues and concerns. Women's Health Issues 7(4), 234-40

Rubin, V., East, P. L. (1999) Adolescents' pregnancy intentions. Journal of Adolescent Health 24, 313-9

Sable, M. R. (1999) Pregnancy intentions may not be a useful measure for research on maternal and child health outcomes. Family Planning Perspectives 31(5), 249-51

Tessaro, I., Campbell M., O’Meara C. et al. (1997) American Journal of Preventive Medicine 13, 38-44

Zachariah, R. (1996) Predictors of psychological well-being of women during pregnancy: replication and extension. Journal of Social Behavior \& Personality 11(1), 127-41 


\section{APPENDIX A: Epidemiologic Studies Depression Scale: CES-D}

How many days (0-7) during the past week have you:

a. been bothered by things that usually don't bother you

b. not felt like eating; your appetite was poor

c. felt you could not shake off the blues even with help from your family or friends

d. felt that you were just as good as other people

e. had trouble keeping your mind on what you were doing

f. felt depressed

g. felt that everything you did was an effort

h. been hopeful about the future

i. thought your life was a failure

j. felt fearful

k. had sleep that was restless

1. been happy

m. talked less than usual

n. felt lonely

o. thought that people were unfriendly

p. enjoyed life

q. had crying spells

r. felt sad

s. felt that people disliked you

t. felt you just couldn't get going 


\section{APPENDIX B: Cohen's Perceived Stress Scale}

In the past month have you:

a. been upset because of something that happened unexpectedly?

b. felt that you were able to control the important things in your life?

c. felt nervous and "stressed"?

d. dealt successfully with irritating life hassles?

e. felt that you were effectively coping with important changes that were occurring in your life?

f. felt confident about your ability to handle your personal problems?

g. felt that things were going your way?

h. found that you could not cope with all the things that you had to do?

i. been able to control irritations in your life?

j. felt that you were on top of things?

k. been angered because of things that happened that were outside of your control?

1. found yourself thinking about things that you have to accomplish?

m. been able to control the way you spend your time?

n. felt difficulties were piling up so high that you could not overcome them? 


\section{APPENDIX C: Rosenberg Self-Esteem Scale}

For each of the following statements, please tell me whether you strongly agree, agree, disagree, or strongly disagree with it.

a. I feel I have a number of good qualities.

b. I feel I do not have much to be proud of.

c. I am able to do things as well as most other people.

d. I wish I could have more respect for myself.

e. I certainly feel useless at times.

f. At times, I feel I am no good at all.

g. I feel that I am a person of worth at least on an equal basis with others.

h. I take a positive attitude toward myself.

i. $\quad$ All in all, I am inclined to feel I am a failure.

j. On the whole, I am satisfied with myself. 